\title{
A aprovação da Resolução CNS n 510/2016 é um avanço para a ciência brasileira
}

\section{The approval of Resolution CNS no. 510/2016 is a progress for Brazilian science}

\author{
Iara Coelho Zito Guerriero ${ }^{a}$ \\ (D) https://orcid.org/0000-0001-7381-5516 \\ Email: iarag®alumni.usp.br \\ Maria Cecilia Minayo ${ }^{b}$ \\ (D) https://orcid.org/0000-0001-6187-9301 \\ Email: cecilia®claves.fiocruz.br \\ ${ }^{a}$ Centro Universitário Saúde $A B C$. Faculdade de Medicina. \\ Santo André, SP, Brasil. \\ ${ }^{\text {b} F u n d a c ̧ a ̃ o ~ O s w a l d o ~ C r u z . ~ R i o ~ d e ~ J a n e i r o, ~ R J, ~ B r a s i l . ~}$
}

\section{Resumo}

A Resolução nº 510/2016 do Conselho Nacional de Saúde determina diretrizes éticas específicas para as ciências humanas e sociais (CHS) e é resultado de anos de trabalho de pessoas e instituições que há muito apontavam a inadequação de uma única orientação de cunho biomédico para pesquisas em diferentes áreas. Discutem-se aqui as principais diferenças entre a pesquisa em CHS e a pesquisa biomédica. A disputa pelo poder de definir o que é ciência caracteriza o campo científico, no qual não cabe a interferência do sistema de Comitês de Ética em Pesquisa/Comissão Nacional de Ética em Pesquisa, cuja missão é a proteção do participante de pesquisa. Comentam-se seis mudanças que a Resolução $n^{0}$ 510/2016 traz. Observa-se que as normas brasileiras sobre ética em pesquisa ainda são restritas. No âmbito internacional, vários códigos de ética são mais abrangentes. A Noruega dispõe de diretrizes específicas para as ciências sociais, humanas, jurídicas e teológicas, que contemplam o valor e a função social da pesquisa; os interesses da sociedade; a necessidade da liberdade para investigar; o papel e os interesses dos gestores acadêmicos; os princípios e os interesses dentro das comunidades científicas, inclusive em suas relações com os estudantes; a responsabilidade das agências de financiamento; as consequências dos resultados das pesquisas; e a popularização da ciência.

Palavras-chave: Comitê de Ética em Pesquisa; Conep; Pesquisa Qualitativa; Epistemologia; Saúde Coletiva; Ciências Humanas e Sociais.

\section{Correspondência}

Iara Coelho Zito Guerriero

Rua Cayowaá, 2.251, Sumaré. São Paulo, SP, Brasil. CEP ol258-oı. 
The Brazilian National Health Council's Resolution no. 510/2016 states the specific ethical procedures for social science and humanities (SSH) research. It is the result of many people's work who, for a long time, have been arguing the inadequacy of one single strictly biomedical set of guidelines supposed to be applied in all areas. The main differences between SSH research and biomedical research are discussed in this article. The fight for the power to state what science is characterizes the scientific field, in which the interference of the Research Ethics Board/Brazilian Commission on Research Ethics system is not adequate, because the mission of this system is to protect research participants. We discuss six changes brought by Resolution no. 510/2016. Brazilian guidelines on research ethics are prominently narrow. At the international level, many research codes are broader. Norway has specific guidelines for research in Social Science, Humanities, Law and Theology, which include the discussion on research's social value and function; society's interests; the need for academic freedom to conduct research considering ethical procedures; the role and interests of academic managers; principles and interests within academic communities, including their relationship with students; funding agents' responsibility; researches' results consequences; and science popularization.

Keywords: Research Ethics Board; Conep; Qualitative Research; Epistemology; Collective Health; Social Sciences and Humanities.
Este texto tem a finalidade de apresentar a relevância para a área de pesquisa no País da Resolução ${ }^{0} 510$ do Conselho Nacional de Saúde (CNS), promulgada em 2016 (Brasil, 2016). Ela determina procedimentos éticos específicos para investigações com seres humanos, que utilizam abordagens das ciências humanas e sociais (CHS) e é a materialização dos resultados de anos de trabalho e da mobilização de muitas pessoas e instituições que há muito apontavam a inadequação de uma única orientação, de cunho estritamente biomédico, para pesquisas em diferentes áreas (Guerriero, 2016).

$\mathrm{O}$ artigo inicia-se informando ao leitor a partir de que perspectiva e com que estado de espírito ele é escrito. 0 texto contém a reflexão das autoras, que conduzem pesquisas e orientam estudantes sobre os problemas sociais e emocionais que afetam a saúde, com ênfase nos estudos qualitativos e por triangulação de métodos. Olhandose dessa posição, a dicotomia que parece haver entre CHS e saúde desaparece, pois a saúde coletiva se define como um campo de produção de conhecimentos e de práticas, assentado sobre o tripé formado pelas CHS, pela epidemiologia e pelas ciências da administração e gestão. Longe de haver um distanciamento entre CHS e saúde, as primeiras constituem um dos eixos estruturantes do campo que trabalha com gente - enquanto indivíduo e coletividade. Gente não só é passível de adoecimento no corpo, cuja explicação remete às ciências médicas, mas é, principalmente, capaz de expressar suas emoções e sua dor, qualificála e simbolizar seus sentimentos, comportamentos e ações.

O estudo também compara alguns aspectos da Resolução no 510/2016 com a no 466/2012 (Brasil, 2013a). Esta última, adequada para a ética nas pesquisas biomédicas, vinha sendo exigida para qualquer investigação da área da saúde. Assim como no Brasil, e há bastante tempo, os cientistas das áreas sociais e humanas de vários países vêm se incomodando com as exigências homogeneizadoras dos instrumentos normativos sobre ética em pesquisa, oriundos e adequados para investigações biomédicas, mas impróprios para estudos de seu campo. A literatura das CHS mostra desde uma 
espécie de revolta dos cientistas sociais contra as exigências descabidas - é o caso de Hammerley (2009), que escreveu um artigo cujo título é "The evil of ethical regulation" - a esforços para esclarecer as diferenças (Israel; Hay, 2006; Webster; Lewis; Brown, 2014), passando pelo empenho em estabelecer e comparar os princípios diversos (Miller; Boulton, 2007; Miller et al., 2002), até a oficialização de procedimentos específicos por autoridades de diversos países, como Estados Unidos, Canadá, Reino Unido, Nova Zelândia, Austrália e outros. Citase aqui, como exemplo, o documento elaborado pelos e para os cientistas sociais da Noruega, cuja última versão é de 2016 (mas foi pela primeira vez divulgado em 1993) e incorpora, além das ciências sociais tradicionais, as áreas jurídicas e a teologia (Etikkom, 2016). Uma observação interessante sobre os caminhos dessa reflexão em âmbito internacional é que, apesar de haver estudos mais antigos, a maior parte da bibliografia sobre o tema se intensifica a partir dos anos 200o. Ou seja, a oficialização de normas sobre ética de pesquisas em CHS em vários países é um assunto do século XXI.

Também no Brasil data deste século a inciativa dos cientistas sociais e humanos, sob a égide do Conselho Nacional de Saúde (Guerriero; Minayo, 2013). É preciso lembrar que, no País, as resoluções CNS no 1/1988 (Brasil, 1988), nº 196/1996 (Brasil, 1996) e $n^{0} 466 / 2012$ (Brasil, 2013a) (apenas esta última está em vigor) foram construídas tomando como base os documentos elaborados para a área biomédica (Guerriero; Minayo, 2013), a saber: o Código de Nuremberg (1949), a Declaração de Helsinki (1989), os documentos do Council for International Organizations of Medical Sciences (1993) e o Relatório Belmont (1979) que, obviamente, não dão conta dos paradigmas das CHS (Guerriero; Dalari, 2008).

Neste artigo há três ênfases: a discussão de alguns parâmetros de cientificidade das CHS que fundamentam os procedimentos da Resolução $n^{0}$ 510/2016; o que essa resolução modifica em relação à $n^{0} 466 / 2012$ e os aspectos operacionais da resolução em pauta para os Comitês de Ética em pesquisa (CEP). O texto termina com uma reflexão sobre a necessidade de se ampliar a discussão sobre a ética em pesquisa, ainda muito restrita a procedimentos.

\section{Parâmetros de cientificidade das ciências humanas e sociais}

Como o foco deste artigo é a Resolução que trata da ética em pesquisas de CHS, é importante refletir sobre alguns termos que costumam provocar desconfianças dos cientistas tradicionais em relação aos estudos sociais e às humanidades. 0 primeiro é o próprio conceito de cientificidade; o segundo é a relação entre subjetividade e objetividade; o terceiro é conceito de neutralidade (ciências biomédicas) versus o de empatia (CHS).

A cientificidade da pesquisa social comprovase, teoricamente, pelos fundamentos filosóficos e epistemológicos de sua abordagem. Essa cientificidade ancorase na intersubjetividade, na compreensão e na crítica, o que vai na contramão da visão positivista de verdade. Aqui não se trabalha com a verdade, mas com a interpretação das pessoas sobre seus atos. Também não se pretende de antemão explicar os fatos, e sim compreendêlos e contribuir para o avanço da consciência crítica e da ação social transformadora. Os fundamentos da pesquisa social têm razões profundas e históricas.

Tomando como referência apenas o período da ciência moderna, a discussão que a sustenta atravessa 200 anos e tem como berço o pensamento hermenêutico, fenomenológico, histórico e dialético alemão. Nesse sentido, é seminal a obra de Hegel. Este autor, que viveu entre 1770 e 1831, na Fenomenologia do espírito, escrita em 1807, ressalta que a consciência nasce da experiência (Hegel, 1987). Segundo esse filósofo, quem fala de experiência fala de sujeito, e quem fala de sujeito fala de objeto. Assim, a fundamentação de todo saber é resultado de uma gênese ou de uma história que se inicia no plano fenomenológico e que ocorre em oposições sucessivas e dialeticamente articuladas entre as certezas do sujeito e a verdade do objeto. A intenção de Hegel na Fenomenologia do espírito foi a de desmontar a visão filosófica de cisão entre os fenômenos do mundo, da vida e a ciência, tal como autores como Descartes concebiam. Hegel ressalta a face histórica das experiências humanas objetivadas na cultura e sua face dialética, que contrapõe e aproxima o sujeito 
que as vivencia e a verdade do objeto construído por sucessivas oposições.

A obra de Hegel foi seguida pelos fundamentos da fenomenologia desenvolvida por Heidegger (1980) e Husserl (1982), pelos escritos sobre a hermenêutica filosófica de Gadamer (1999), a hermenêutica objetiva de Adorno e Horkheimer (1981), a hermenêutica dialética de Habermas (1987) e pelo historicismo compreensivo de Dilthey (2010). Na sociologia, a linha compreensiva amparase no pensamento originário de Max Weber (1979). Os fundamentos dessa abordagem cruzamse, igualmente, com os escritos de vários teóricos e sociólogos franceses, influenciados pelos pensadores germânicos, como demonstrado nos trabalhos de Maffesoli (1988), Bourdieu (1993), Touraine (1993), Paul Ricoeur (1996), Merleau Ponty (1999) e Sartre (2002), entre outros. A expressão empírica das teorias compreensivas deve muito, em sua origem, à chamada Escola de Chicago, onde nomes importantes como Robert Park e Ernest Burgess (1925), George Hebert Mead (1934), Goffman (1959), Harold Garfinkel (1967) e outros inauguraram abordagens sociologicamente importantes, como interacionismo simbólico, etnobiografia, etnometodologia e teoria da ação. Cada vez mais as ciências sociais contemporâneas aproximamse do modelo compreensivo, embora o positivismo continue a ser uma forma de pensamento e de ação seguida por muitos pesquisadores. O importante é saber que é histórica e persistente a busca dos cientistas em compreender o ser humano em sua ação, reflexão, simbologia e expressão (Nunes, 2005).

A dialética da subjetividade que se expressa em todo ato e relação humana versus a objetividade do que o ser humano produz é um problema epistemológico. A subjetividade entranha toda ação humana, inclusive a da pesquisa biomédica: não há como negála. Mas qualquer pesquisa social que a considere como uma condição de seu trabalho atua para produzir conhecimento o mais possível fundamentado em teoria, método, técnicas e análises contextualizadas (Denzin; Lincoln, 2000).
Embora os procedimentos minimizem os vieses que estão presentes em qualquer investigação, não existe nenhum estudo neutro nem nas ciências biomédicas e nem nas CHS (Minayo; Guerriero, 2014). Uma diferença entre ambas é que determinadas etapas do conhecimento no primeiro caso podem ser realizadas com menos intervenção do sujeito, e nas CHS pode haver neutralidade em procedimentos, mas a chave de qualquer conhecimento de pessoas, grupos e relações são a empatia e a intersubjetividade que Gadamer (1999) define como a capacidade de se colocar no lugar do outro. Quanto mais intensa a comunicação e a compreensão maior a possibilidade de entendimento da situação.

A maioria das dúvidas para a aprovação de projetos nos CEP no setor da saúde referese à utilização de pesquisas do método qualitativo. Portanto, é fundamental assinalar algumas de suas características que, ao contrário de tornálo fraco, são sua fortaleza: (1) elas são realizadas no local onde as pessoas estão, na sua vida cotidiana, pois é importante para o pesquisador conhecêlas no seu ambiente habitual. (2) O pesquisador faz observação, participante ou não, entrevista ou conduz um grupo focal, ou usa outras técnicas como forma de aproximação. (3) Muitos estudiosos preferem nomear seu trabalho em campo como "geração do material” e não como "coleta de dados", porque entendem que a construção de significados acontece na interação humana, através do diálogo, num processo intersubjetivo em que cada pessoa faz sua síntese pessoal, pois, "a rigor, não existe nada 'dado' em pesquisa: tudo é construído e construído por alguém que é sujeito, tem interesses e ideologia" (Minayo, 2012, p. 88). (4) A investigação é um processo dinâmico, que se atualiza a todo momento da interação. O investigador sabe que trabalha, no entanto, com regularidades, pontos comuns, relevâncias grupais ao lado das singularidades e dos evasivos da vida social. (5) 0 pesquisador é assumidamente parte do campo de sua pesquisa, e não há a intenção de ser isento (Minayo, 2010). No entanto, é importante que mantenha vigilância permanente de seu comportamento, buscando 
ser sempre um indagador mais que um colega (sua preparação teórica contribuirá para isso). (6) O material a ser analisado na pesquisa com vistas a atingir o objetivo proposto é um construto de primeira ordem (Schütz, 1967) gerado na relação entre participante e pesquisador, no espaço intersubjetivo. É fundamental que ele evolua para um construto de segunda ordem (Schütz, 1967), analítico, referenciado e reflexivo. Ou seja, ele deve ser balizado de forma compreensiva e crítica, buscando relevâncias e sendo contextualizado e confrontado com a bibliografia nacional e internacional pertinente.

Tendo em vista o processo intersubjetivo, concluise que os resultados da pesquisa qualitativa não são replicáveis a priori, pois quando se muda quem conduz uma interlocução, o material gerado também poderá ser diferente. Vejase o seguinte exemplo. Numa investigação sobre sexualidade com adolescentes do sexo masculino, eles não responderão da mesma maneira se a entrevistadora for uma mulher de 50 anos, com idade próxima à de sua mãe ou um homem jovem de cultura ou interesses semelhantes, pois nem as palavras que utilizarão serão as mesmas, nem o que relatarão. Essa contingência alerta para a necessidade de se preparar muito bem todos os passos de um estudo. E quando realizado, ser cuidadosamente descrito, permitindo ao leitor entender as circunstâncias em que foi efetuado. Mas há meios de se encontrar questões passíveis de serem generalizadas e que digam respeito a temas amplos. Como lembram Adorno e Horkheimer (1981), em sua "hermenêutica objetiva”, a pesquisa social é intersubjetiva, mas deve fugir do subjetivismo ao descortinar a lógica que existe entre as estruturas de reprodução social e as estruturas de transformação, presentes em qualquer contexto.

Além da pesquisa qualitativa tradicional, também são comuns na área da saúde estudos qualitativos do tipo pesquisa-ação, pesquisa participativa ou mesmo pesquisa baseada na comunidade. Para todos eles, além dos métodos e técnicas já bastante conhecidos, há o objetivo direto de trazer mudanças em relação ao problema em pauta. Para isso, a equipe de pesquisa precisa definir, junto com os participantes, os objetivos do estudo, quem serão os participantes, as estratégias em campo, a discussão dos resultados e para quem eles serão apresentados. Autores como Minkler e Wallerstein (2008) conduzem pesquisas baseadas na comunidade e costumam incluir entre seus objetivos capacitar os participantes para que se tornem pesquisadores, incluindoos como assistentes. Muitos se tornam coautores dos artigos gerados a partir da investigação.

As CHS se caracterizam pela diversidade de correntes de pensamento, em contraposição a outras áreas, como a biomedicina, cujos parâmetros são bastante rígidos, regulados e estabelecidos. Para mostrar essas diferenças, discutemse aqui dois tipos de pesquisas que costumam tramitar no Sistema CEP/Comissão Nacional de Ética em Pesquisa (Conep): as de novos medicamentos que seguem as normas da ética em pesquisas biomédicas e as de cunho qualitativo. São apenas exemplos, pois as pesquisas biomédicas não se limitam a testes de medicamentos, e muitas do campo das CHS utilizam abordagens quantitativas ou ambas de maneira articulada.

A partir da atuação no Sistema CEP/Conep, identificamse as seguintes características dos testes de novos medicamentos: (1) O estudo tem o pressuposto de que qualquer pesquisador, ao utilizar a mesma metodologia, chegue a resultados iguais, permitindo investigações e abordagens replicáveis. (2) Geralmente os testes são realizados em hospitais ou clínicas. 0 participante tem que se deslocar das suas atividades cotidianas e ir aonde o pesquisador está para lhe fornecer informações, material biológico e receber o medicamento. (3) Cada projeto descreve cuidadosamente o medicamento em estudo, como número de doses ofertadas ao participante e como e com que o produto será comparado, entre outras informações. (4) Usualmente tais estudos são administrados no formato cego ou duplo cego, respectivamente quando o participante não sabe o que está tomando ou quando nem ele nem o pesquisador responsável pelo estudo sabem. Tais medidas visam a mantêlos isentos durante o processo da pesquisa, 
evitandose erros ou vieses. (5) A divulgação dos resultados é feita para a comunidade científica. Aos participantes são dirigidas estratégias de marketing para divulgação do produto quando ele estiver disponível para venda no país. (6) 0 objetivo de todo o processo é o patenteamento do medicamento e sua comercialização.

Numa pesquisa em CHS, em geral, (1) o foco é na construção de significados do processo de saúde e doença, da gestão e da política do setor, uma vez que as crenças têm efeitos sobre o corpo, as emoções e as ações, como lembra William Thomas (1970, p. 246), segundo o qual "quando alguém acredita que algo é real, ele se torna real nas suas consequências". (2) É o pesquisador que se desloca e vai ao campo. (3) Em lugar do anonimato, a essência de sua atividade é a intersubjetividade, pois existe uma coconstrução dos significados a partir da visão das pessoas sobre sua situação. (4) A palavra central da interrelação é a empatia (e não o anonimato), e quanto mais ela ocorrer melhor será a compreensão da lógica pessoal e grupal em relação ao tema em estudo. (5) As abordagens sociais e das áreas de humanas, em geral, visam a obter um tipo diferente de resultados replicáveis em relação ao modelo biomédico, ao conhecer os pensamentos, sentimentos, crenças, valores e condutas de pessoas que compõem um grupo determinado, com suas necessidades, problemas e fortalezas. Na narrativa dos entrevistados e em sua ação, o pesquisador observa várias camadas de informação, inclusive seu sentido mais profundo, que contém a compreensão e as contradições da história e da realidade. (6) A divulgação dos dados, além de abranger a comunidade científica, deve focalizar os interlocutores ouvidos e outros grupos com o mesmo perfil. Portanto, uma pesquisa com abordagem social em saúde é estratégica para a reflexão e a promoção de mudanças. (7) 0 propósito da pesquisa, em geral, não visa ao mercado, mas a compreender a situação em foco e, junto com os interlocutores, encontrar novas formas de agir.

No Quadro 1, ilustramse as diferenças entre a lógica biomédica e a social e humana.

Diante de tantas diferenças, como identificar o que é uma boa pesquisa científica? Ou ainda, o que é ciência? Essa é mesmo uma questão difícil de responder de forma peremptória. Portanto, não cabe ao Sistema CEP/Conep cristalizar uma única definição de ciência, como ocorreu com as Resoluções no 1/1988, a nº 196/1996 e a $n^{0} 466 / 2012$. Essa foi a justificativa que marcou a elaboração da Resolução ${ }^{0}$ 510/2016, que trata das pesquisas em CHS.

Quadro I - Diferenças de abordagem entre uma pesquisa para teste de medicamentos e uma abordagem qualitativa

\begin{tabular}{|c|c|c|}
\hline & Teste de medicamento & Pesquisa qualitativa \\
\hline Local & Hospital, clínica, universidade & Vida cotidiana \\
\hline Atividades da pesquisa & $\begin{array}{l}\text { Avaliação clínica, coleta de material } \\
\text { biológico }\end{array}$ & Observação, entrevista, grupo focal \\
\hline Proposta & Coleta de dados & Geração do material \\
\hline Pesquisa & Replicável & Auditável \\
\hline Divulgação & $\begin{array}{l}\text { Estratégias de marketing para venda } \\
\text { do medicamento após liberado para } \\
\text { comercialização }\end{array}$ & $\begin{array}{l}\text { Apresentação dos resultados para os } \\
\text { participantes e sua comunidade, além } \\
\text { dos eventos e publicações científicas }\end{array}$ \\
\hline Pesquisador & $\begin{array}{l}\text { Busca estratégia para não interferir no } \\
\text { campo da pesquisa }\end{array}$ & $\begin{array}{l}\text { É assumidamente parte do campo da } \\
\text { pesquisa }\end{array}$ \\
\hline
\end{tabular}




\section{0 que muda com a Resolução $n^{\circ}$ 510/2016 em relação à 466/2012?}

A Resolução $n^{0}$ 510/2016 está em vigor desde a sua publicação no Diário Oficial da União, em 24 de maio de 2016. Em seu art. 2, define o que é considerada pesquisa em CHS:

aquelas que se voltam para o conhecimento, compreensão das condições, existência, vivência e saberes das pessoas e dos grupos, em suas relações sociais, institucionais, seus valores culturais, suas ordenações históricas e políticas e suas formas de subjetividade e comunicação, de forma direta ou indireta, incluindo as modalidades que envolvam intervenção.

Essa Resolução se aplica a toda pesquisa que se inclua nessa definição e que não tenha intervenção direta no corpo humano.

Neste texto, foram selecionadas seis mudanças que a Resolução $n^{0}$ 510/2016 traz em relação à $n^{0}$ 466/2012: definição do que não precisa ser avaliado pelo Sistema CEP/Conep; discernimento entre processo e registro de consentimento e assentimento livre e esclarecido; avaliação de mérito científico; explicitação das etapas que antecedem ao projeto completo; relação entre a Resolução $n^{0} 510$ e a 466; e composição do Sistema CEP/Conep.

\section{Situações em que as pesquisas não necessitam passar por comitê de ética}

Os casos estão previstos no parágrafo único do art. $1^{0}$ :

1) Pesquisa de opinião pública. Por exemplo, investigação sobre intenção de voto, que acontece em espaço público. Considerese esse tipo de estudo realizado no centro de São Paulo. O transeunte é convidado a informar sua intenção. Em seguida, o entrevistador registra sexo, idade, faixa de renda e escolaridade. 0 pesquisador não sabe a identidade do participante.

2) Pesquisa que utiliza informações de acesso público, nos termos da Lei $n^{0} 12.527$, de 18 de novembro de 2011, segundo a qual todo documento produzido ou sob a guarda do Estado é de natureza pública, a menos que permita a identificação individual ou implique em questões de segurança pública (Brasil, 2011). É o caso de estudos que se baseiam nos dados do Datasus, disponíveis na internet sem necessidade de senha para os acessar.

3) Pesquisa que utiliza informações de domínio público. Um exemplo são as investigações realizadas sobre informações divulgadas em jornais de grande circulação.

4) Pesquisa censitária, que é a de domínio e realização pelo Instituto Brasileiro de Geografia e Estatística (IBGE).

5) Pesquisa com bancos de dados, cujas informações são agregadas, sem possibilidade de identificação individual. Incluemse as não disponíveis na internet.

6) Revisão da literatura científica, uma vez que o pesquisador trabalha com artigos, livros e outros materiais já publicados e, portanto, de domínio público.

7) Pesquisa reflexiva, voltada ao aprofundamento teórico de situações que emergem da prática profissional, desde que não revele dados que identifiquem pessoas. Nesse caso, não há procedimentos típicos de investigação científica, ou seja, não há, por exemplo, assuntos específicos a serem abordados e nem instrumentos de pesquisa a serem aplicados.

8) Atividade realizada com o intuito de melhorar o processo educativo, o ensino ou treinamento de alunos de graduação, de curso técnico, ou de pós-graduação, sem caráter de pesquisa científica. É o caso de uma entrevista como treinamento proposto pela professora de metodologia de pesquisa qualitativa com a finalidade de discussão da técnica.

Há duas situações previstas na Resolução $n^{0} 510 / 2016$ em que o descrito no art. $1^{0}$, item 8 , não se aplica, e estão descritas nos $\S 1^{\circ}$ e $\S 2^{\circ} .0$ § $1^{\circ}$ menciona que não se enquadram no citado inciso os trabalhos de conclusão de curso (TCC), monografias e similares que trabalhem com seres humanos. Ou seja, embora esses projetos tenham o propósito primordial de que o aluno aprenda a fazer pesquisa, não implica 
isenção de submissão ao Sistema CEP/Conep e, por isso, seus autores devem apresentar o protocolo de pesquisa ao Sistema CEP/Conep. Esse item menciona explicitamente que os TCC que não se enquadrem nos itens de I a VII precisam ser submetidos à revisão ética pelo Sistema CEP/Conep. $O \S 2^{\circ}$ trata de projetos de investigação oriundos e resultantes do planejamento ou da execução da atividade de educação, ensino ou treinamento. Seus autores devem, de forma obrigatória, apresentar o protocolo de pesquisa ao Sistema CEP/Conep. Recuperando o exemplo da professora de metodologia: no momento em que ela tiver a intenção de analisar o conteúdo das entrevistas realizadas no treinamento de seus alunos, precisa elaborar um projeto de pesquisa e enviálo para revisão ética do Sistema.

\section{Discernimento entre processo e registro de consentimento e assentimento livre e esclarecido}

A Resolução n ${ }^{0}$ 510/2016 trata do consentimento e do assentimento livre e esclarecido no art. 15, que também estabelece diferentes modalidades de registro, respeitandose a maior diversidade possível e legítima de formas de interação com os participantes das pesquisas.

É importante ressaltar que a Resolução n 510/2016 não utiliza a palavra “termo", justamente para evitar uma similaridade com pesquisas que trabalham com outros paradigmas e estabelecem relações muito diferentes entre pesquisadores e participantes. A palavra "registro" foi escolhida durante o processo de elaboração da Resolução $n^{0}$ 510/2016 exatamente para explicitar que há diferenças e especificidades nas pesquisas em CHS. Não cabe, portanto, a referência a Termo de Consentimento Livre e Esclarecido ou a Termo de Assentimento Livre e Esclarecido nos projetos CHS.

Assim reza o art. 15:

o Registro do Consentimento e do Assentimento é o meio pelo qual é explicitado o consentimento livre e esclarecido do participante ou de seu responsável legal, sob forma escrita, sonora, imagética, ou outras que atendam às características da pesquisa e dos participantes, devendo conter informações em linguagem clara e de fácil entendimento para o suficiente esclarecimento sobre a pesquisa. (Brasil, 2016)

$0 \S 1^{\circ}$ deste artigo menciona que, quando não houver nenhum registro de consentimento e do assentimento, o pesquisador deverá entregar um documento ao participante que contemple as informações previstas para o consentimento livre e esclarecido sobre a pesquisa, como descrito no art. 17 . Cabe ressaltar que esse documento só é necessário se o processo de consentimento/assentimento livre esclarecido não tiver sido registrado de outra maneira (gravação sonora, imagética ou outras).

No $\S 2^{\circ}$, lê-se que “a obtenção de consentimento pode ser comprovada também por meio de testemunha que não componha a equipe de pesquisa" e que acompanhe a manifestação positiva ou negativa do participante do estudo (Brasil, 2016).

\section{Avaliação de mérito científico}

Esta avaliação exige conhecimento da metodologia utilizada no projeto e dificilmente um CEP terá entre seus membros alguém que dê conta da diversidade teórica e metodológica das CHS. Por isso, o art. 25 estabelece que a avaliação a ser feita pelo Sistema CEP/Conep incidirá somente sobre os aspectos éticos dos projetos, considerando os riscos e a devida proteção dos direitos dos participantes da pesquisa.

$0 \S 1^{0}$ reza que a avaliação científica dos aspectos teóricos dos projetos submetidos nos termos da Resolução n 510/2016 compete a instancias acadêmicas especificas, tais como comissões científicas, bancas de pós-graduação, instituições de fomento à pesquisa, entre outros. Não cabe ao Sistema CEP/Conep a análise do desenho metodológico em si. E no $\S 2^{\circ}$ está escrito que a avaliação a ser realizada pelo Sistema CEP/Conep incidirá somente sobre os procedimentos metodológicos que impliquem riscos aos participantes.

Portanto, não é atribuição do Sistema CEP/ Conep, por exemplo, solicitar o cálculo amostral de uma pesquisa qualitativa. Ou ainda, solicitar o roteiro de entrevista, se o pesquisador informou que ela será aberta e em profundidade. Esses e outros procedimentos equivocados eram frequentemente solicitados. O papel do Sistema CEP/Conep é, 
sobretudo, o de proteção do participante. Por isso, cabelhe avaliar se as ações previstas no processo de investigação podem lhe trazer algum dano e solicitar ao pesquisador que adote medidas para minimizálo.

\section{Explicitação das etapas preliminares}

Nas pesquisas em CHS, nas quais não havia coleta de material biológico, às vezes ficava difícil para o responsável por uma unidade de saúde identificar o início formal do estudo. Costumeiramente, quando pretendia investigar qualquer questão em instituições do setor, o pesquisador solicitava uma reunião com o gestor a fim de obter permissão para realizar seu trabalho e discutir a maneira mais adequada de conduzilo. 0 gestor, por sua vez, com receios de danos aos possíveis entrevistados, exigia aprovação do projeto no Sistema CEP/Conep, o que frequentemente criava um impasse. De um lado, o investigador precisava de permissão para submeter seu projeto ao CEP. De outro, o responsável institucional o exigia antecipadamente. Por isso, o art. 24 estabelece que todas as etapas preliminares necessárias para que o pesquisador elabore seu projeto não são alvo de avaliação do Sistema CEP/Conep.

A Resolução $n^{0}$ 510/2016, no seu art. 2 trata dos termos e definições e explicita quais são essas etapas preliminares: (1) Atividades que o pesquisador tem que desenvolver para averiguar as condições de possibilidade de realização da pesquisa, como investigação documental; contatos diretos com possíveis participantes sem sua identificação e sem o registro público e formal das informações obtidas; visitas às comunidades, aos serviços, conversa com líderes comunitários e outros. (2) Essas ações não se confundem com "estudos exploratórios" ou com "pesquisas piloto", modalidades que devem ser alvo das comissões de ética.

Relação entre a Resolução $n^{o} 510 / 2016$ e a $n^{\circ} 466 / 2012$

O art. 32 da Resolução 510/2016 trata de sua relação com a Resolução no 466/2012. Quando não houver prejuízo ao disposto na Resolução $\mathrm{n}^{0}$ 510/2016, aplicase o disposto nos itens VII, VIII, IX e X da Resolução nº 466/2012. No parágrafo único do mesmo art. 32, está escrito que, em situações não contempladas pela Resolução no 510/2016, os princípios éticos contidos na Resolução CNS $n^{\circ}$ 466/2012 prevalecem. Em relação a esse parágrafo, cabe destacar que a minuta da Resolução n ${ }^{0}$ 510/2016 foi elaborada contemplando todos os cuidados presentes na Resolução no 466/2012, na medida em que forem aplicáveis às pesquisas em CHS. Se existirem lacunas, o correto é aplicarse os princípios de autonomia, beneficência, não maleficência, justiça e equidade, previstos na Resolução $n^{0}$ 466/2012. É claro que princípios não são procedimentos e não devem ser solicitados pelos CEP, com base na Resolução no 466/2012, aos projetos de CHS.

\section{Composição do Sistema CEP/Conep}

Por causa dos múltiplos referenciais teóricometodológicos das disciplinas que compõem o campo da saúde, é fundamental que os CEP e a Conep sejam compostos por membros de diferentes áreas. Com relação aos CEP, o art. 26 afirma que a análise dos projetos de pesquisa cobertos pela Resolução $n^{0}$ 510/2016 só poderá ocorrer nos comitês que comportarem representação equânime de membros das ciências humanas e sociais e biomédicas. E os projetos de CHS devem ser revistos pelos membros qualificados dentro da área de conhecimento. Segundo o art. 30 da Resolução no 510/2016, devese estimular o ingresso de pesquisadores e profissionais atuantes nas CHS nos colegiados dos CEP já existentes e manter a interdisciplinaridade nos que forem criados.

\section{Aspectos operacionais dos CEP}

O CEP será composto por no mínimo sete membros, entre os quais pelo menos um representante de usuários, respeitandose a proporcionalidade pelo número de membros. No mínimo 50\% deles devem comprovar experiência em pesquisa. Esse percentual pode variar de acordo com as especificidades da instituição e dos temas a serem analisados. O CEP deve ter sempre caráter multidisciplinar, participação de homens e mulheres, e mais que a metade de seus membros não deve pertencer à mesma categoria profissional. Para seu bom funcionamento, poderá contar com consultores técnicos ad hoc, pertencentes ou não à instituição. É importante que a composição dos CEP seja adequada 
aos projetos que analisa, sendo, portanto, possível se organizar comitês específicos para avaliar projetos de CHS (Norma Operacional $n^{0} 1 / 2013$ ) (Brasil, 2013b).

Portanto, é possível e desejável a organização de CEP voltados especificamente para a revisão ética de projetos CHS, se os projetos a serem revistos por esse CEP forem dessas áreas. Um CEP composto por um filósofo, um sociólogo, um antropólogo, um psicólogo, uma assistente social, um advogado e um geógrafo, além do representante de usuário, se tiver número semelhante de homens e mulheres com experiência em pesquisa, está dentro das normas.

Na mesma direção, com relação à Conep, lêse na Resolução no 510/2016, art. 33: “a composição da Conep respeitará a equidade entre os membros titulares e suplentes das áreas de ciências humanas e sociais e das demais na sua composição, garantindo a representação equilibrada na elaboração de normas e no gerenciamento do Sistema”.

\section{Considerações finais}

A Resolução $n^{0}$ 510/2016 é uma novidade importante para o campo científico brasileiro, pois ela reconhece oficialmente o papel diferenciado das CHS e de seus métodos nas pesquisas com seres humanos, em particular as da área da saúde. Esperase que essa resolução colabore também para que o Sistema CEP/ Conep trate todos os pesquisadores com a mesma consideração, pois não cabe a ele tomar partido na definição do que seja ciência. A Resolução $n^{0} 510$ está em vigor desde maio de 2016. Garantir o texto já é um avanço, mas não é tudo. Como já afirmado em Guerriero e Bosi (2015), é importante desencadear um processo de efetivação de tais diretrizes, o que engloba dois aspectos fundamentais: um concernente à construção de uma nova cultura no interior da Conep e dos mais de 800 CEP brasileiros, e na comunidade acadêmica; o outro trata de uma ação comunicativa em vários outros planos.

Ao finalizar, é importante assinalar que a reflexão sobre ética no Sistema CEP/Conep ainda é bastante restrita, o que pode ser atribuído ao excesso de trabalho que o cotidiano demanda. Voltando à experiência internacional, vários códigos de ética são muito mais abrangentes que o cuidado dispensado somente à regulação dos projetos. Citando o código da Noruega, que é específico para as ciências sociais, humanas, jurídicas e teológicas e tem várias revisões, suas orientações não se limitam às normas aplicadas ao trabalho individual do pesquisador (Etikkom, 2016). Ele contempla o valor e a função social da pesquisa; os interesses da sociedade; a necessidade da liberdade para investigar; o foco na pessoa; o papel e os interesses dos gestores das instituições acadêmicas; os princípios e os interesses das comunidades científicas, inclusive em suas relações com os estudantes; a responsabilidade das agências de financiamento; as consequências dos resultados das pesquisas; e a popularização da ciência. Portanto, dentro dessa perspectiva, entendese que os procedimentos previstos na Resolução $n^{\circ}$ 510/2016 e na $n^{\circ} 466 / 2012$ são parte de um conjunto de normas sociais, políticas, econômicas e culturais no interior das quais transita a ética em pesquisa.

\section{Referências}

ADORNO, T.; HORKHEIMER, M. Sociológica.

Madrid: Taurus, 1981.

BOURDIEU, P. La misère du monde. Paris: Seuil, 1993.

BRASIL. Ministério da Saúde. Conselho Nacional de Saúde. Resolução $n^{0}$ 1, de 13 de junho de 1988. Dispõe as normas para a pesquisa em saúde. Diário Oficial da União, Brasília, DF, 14 jun. 1988.

BRASIL. Ministério da Saúde. Conselho Nacional de Saúde. Resolução no 196 , de 10 de outubro de 1996. Aprova diretrizes e normas regulamentadoras de pesquisas envolvendo seres humanos. Diário Oficial da União, Brasília, DF, 11 out. 1996.

BRASIL. Lei ${ }^{0} 12.527$, de 18 de novembro de 2011. Regula o acesso a informações previsto no inciso XXXIII do art. $5^{\circ}$, no inciso II do $\S 3^{\circ}$ do art. 37 e no $\S 2^{\circ}$ do art. 216 da Constituição Federal e dá outras providências. Diário Oficial da União, Brasília, DF, 18 nov. 2011. Disponível em: <http://bit.ly/3oFxCqW>. Acesso em: 2 abr. 2018.

BRASIL. Ministério da Saúde. Conselho Nacional de Saúde. Resolução ${ }^{\circ}$ 466, de 12 de dezembro 
de 2012. Trata sobre as diretrizes e normas regulamentadoras de pesquisa envolvendo seres humanos. Diário Oficial da União, Brasília, DF, 13 jun. $2013 a$.

BRASIL. Ministério da Saúde. Conselho Nacional de Saúde. Norma Operacional $n^{0} 1$, de 12 de setembro de 2013. Dispõe sobre a organização e funcionamento do Sistema CEP/CONEP, e sobre os procedimentos para submissão, avaliação e acompanhamento da pesquisa e de desenvolvimento envolvendo seres humanos no Brasil. Diário Oficial da União, Brasília, DF, 30 set. 2013b. Disponível em: <http://bit.ly/3oFJtoX>. Acesso em: 2 abr. 2018.

BRASIL. Ministério da Saúde. Conselho Nacional de Saúde. Resolução n ${ }^{\circ}$ 510, de 7 de abril de 2016. Trata sobre as diretrizes e normas regulamentadoras de pesquisa em ciências humanas e sociais. Diário Oficial da União, Brasília, DF, 24 maio 2016.

DENZIN, N.; LINCOLN, Y. S. (Ed.). Handbook of qualitative research. Thousand Oaks: Sage, 2000.

DILTHEY, W. Understanding the human world. Nova Jersey: Princeton University Press, 2010. (Selected Papers).

ETIKKOM - NORWEGIAN NATIONAL RESEARCH ETHICS COMMITTEES. Guidelines for research ethics in the social sciences, humanities, law and theology. In: ETKKOM. The Norwegian National Research Committees: ethical guidelines for research. Oslo: 2016. Disponível em: <http://bit. ly/2zq7iVY>. Acesso em: 10 mar. 2018.

GADAMER, H.G. Verdade e método: traços fundamentais de uma hermenêutica filosófica. Petrópolis: Vozes, 1999.

GARFINKEL, H. Studies in ethnomethodology. Nova Jersey: Prentice-Hall, 1967.

GOFFMAN, E. The presentation of self in everyday life. Edimburgo: Anchor Books, 1959.

GUERRIERO, I. C. Z. Resolução n ${ }^{0} 510$ de 7 de abril de 2016 que trata das especificidades éticas das pesquisas nas ciências humanas e sociais e de outras que utilizam metodologias próprias dessas áreas. Ciência \& Saúde Coletiva, Rio de Janeiro, v. 21, n. 8, p. 26192629, 2016. Disponível em: <http://bit.ly/2LiegYc>. Acesso em: 27 ago. 2019.

GUERRIERO, I. C. Z.; BOSI, M. L. M. Ética em pesquisa na dinâmica do campo científico: desafios na construção de diretrizes para ciências humanas e sociais. Ciência \& Saúde Coletiva, Rio de Janeiro, v. 2o, n. 9, p. 2615-2624, 2015.

GUERRIERO, I. C. Z.; DALARI, S. G. The need for adequate ethical guidelines for qualitative health research. Ciência \& Saúde Coletiva, Rio de Janeiro, v. 13, n. 2, p. 303311, 2008. Disponível em: <http:// bit.ly/2Zr2V7L $>$. Acesso em: 27 ago. 2019.

GUERRIERO, I. C. Z.; MINAYO, M. C. S. O desafio de revisar aspectos éticos das pesquisas em ciências sociais e humanas: a necessidade de diretrizes específicas. Physis, Rio de Janeiro, v. 23, n. 3, p. 763782, 2013. Disponível em: <http://bit. ly/2HtZZBo>. Acesso em: 27 ago. 2019.

HABERMAS, J. Hermenêutica e dialética. Porto Alegre: LP\&M, 1987.

HAMMERLEY, M. Against the ethicists: on the evil of ethical regulation. International Journal of Social Research Methodology, Abingdon, v. 12, n. 3 , p. 20112225, 2009.

HEGEL, G. W. F. Fenomenología del espíritu. México: Fondo de Cultura Económica, 1987.

HEIDEGGER, M. O ser e o tempo. São Paulo: Abril, 1980. (Coleção Os Pensadores).

HUSSERL, E. General introduction to a pure phenomenology. Den Haag: Martinus Nijhoff, 1982.

ISRAEL, M.; HAY, I. Research ethics for social scientists. Londres: Sage, 2006.

MAFFESOLI, M. La connaissance ordinaire: précis de sociologie compréhensive. Paris: Klincksieck, 1988.

MEAD, G. H. Mind, self and society. Chicago:

University of Chicago Press, 1934.

MERLEAU-PONTY, M. Fenomenologia da percepção. São Paulo: Martins Fontes, 1999.

MILLER, T.; BOULTON, M. Changing construction of informed consent: qualitative research and complex 
social words. Social Science \& Medicine, Amsterdã, v. 65, n. 11, p. 21992211, 2007. Disponível em: <http:// bit.ly/2Lc6Gst>. Acesso em: 27 ago. 2019.

MILLER, T. et al. Ethics in qualitative research. Londres: Sage, 2002.

MINAYO, M. C. S. O desafio do conhecimento: pesquisa qualitativa em saúde. 12. ed. São Paulo: Hucitec, 2010.

MINAYO, M. C. S.; GUERRIERO, I. C. Z. Reflexividade como éthos da pesquisa qualitativa. Ciência \& Saúde Coletiva, Rio de Janeiro, v. 19, n. 4, p. 11031112, 2014. Disponível em: <http://bit. ly/2ZmSNS2>. Acesso em: 27 ago. 2019.

MINKLER, M.; WALLERSTEIN, N. (Ed.). Communitybased participatory research: from process to outcomes. São Francisco: Jossey-Bass, 2008.

NUNES, E. D. A metodologia qualitativa em saúde: dilemas e desafios. In: BARROS, N. F.; CECATTI, J. G.; TURATO, E. R. (Org.). Pesquisa qualitativa em saúde. Campinas: Unicamp, 2005. p. 15-24.

PARK, R.; BURGESS, E. W. The city: suggestions for investigation of human nature in the urban environment. Chicago: University of Chicago Press, 1925 .

RICOEUR, P. Teoria da interpretação: o discurso e o excesso de significação. Lisboa: Edições 70, 1996.

SARTRE, J. Crítica da razão dialética. Rio de Janeiro: DP\&A, 2002.

SCHÜTZ, A. The phenomenology of the social world. Chicago: Northwestern University Press, 1967.

THOMAS, W. The definition of situation. In: COSER, L. A.; ROSEMBERG, B. (Ed.). Sociological theories: a book of readings. Toronto: McMillan Company, 1970. p. 245-247.

TOURAINE, A. Le retour de l'acteur: essai de sociologie. Paris: Fayard, 1993.

WEBER, M. Ensaios de sociologia. Rio de Janeiro: Jorge Zahar, 1979.

WEBSTER, S.; LEWIS, J.; BROWN, A. Ethical considerations in qualitative research. In: RITCHIE, J.; LEWIS, J. (Ed.). Qualitative research practice: a guide for social sciences students and research. Londres: Sage, 2014. p. 77107.

\section{Contribuição dos autores}

As autoras contribuíram igualmente para a elaboração deste artigo.

Recebido: 12/03/2019

Aprovado: 27/06/2019 